19,04

\title{
Анализ тепловых характеристик монокристаллов парателлурита методом прямоугольной тепловой волны
}

\author{
(C) О.В. Малышкина, М.Ю. Гавалян, Г.С. Шишков, И.А. Каплунов, А.И. Колесников, Н.В. Айдинян \\ Тверской государственный университет, \\ Тверь, Россия \\ E-mail: Olga.Malyshkina@mail.ru \\ (Поступила в Редакцию 4 апреля 2016 г.)
}

Показано, что при исследовании пироэлектрическим методом прямоугольной тепловой волны тепловых характеристик объемных несегнетоэлектрических материалов с малым коэффициентом теплопроводности необходимо решать задачу теплопроводности для трехслойной системы. Исследованы тепловые характеристики кристалла парателлурита различных кристаллографических направлений. Установлена зависимость коэффициента теплопроводности от кристаллографического направления.

Работа выполнена в ЦКП Тверского государственного университета при поддержке Минобрнауки РФ. Исследования кристаллов парателлурита проведены в рамках реализации ФЦП „Исследования и разработки по приоритетным направлениям развития научно-технологического комплекса России на 2014-2020 гг.“, соглашение 14.574.21.0113 (RFMEFI57414X0113), решение задачи прохождения температурной волны через многослойную систему - в рамках выполнения проектной части государственного задания № 11.1937.2014K.

\section{1. Введение}

Монокристаллы парателлурита $\left(\alpha-\mathrm{TeO}_{2}\right)$ являются одним из самых эффективных и востребованных акустооптических материалов, применяемых в светозвукопроводах для видимого и среднего ИК-диапазонов длин волн. В светозвукопроводах работающих акустооптических устройств происходит выделение тепла, которое может в определенной степени изменять все физические свойства материала и, следовательно, влиять на характеристики акустооптического взаимодействия [1-4]. Теплофизические параметры материала также актуальны при совершенствовании способа выращивания кристаллов парателлурита из расплава.

В настоящей работе реализовано применение метода прямоугольной тепловой волны (TSW) [5-10] для исследования теплофизических характеристик пластин кристалла парателлурита, вырезанных перпендикулярно кристаллографическим направлениям [110], [110], [010] и [001]. Исследуемые монокристаллы парателлурита выращивались методом Чохральского в Тверском государственном университете. Вытягивание в процессе роста проводилось в направлении [1ㅣㅣ].

\section{2. Теория и методология исследования}

В основе метода TSW лежат измерения пироэлектрического эффекта с использованием прямоугольно модулированного теплового потока (т.е. при периодическом изменении температуры образца). Этот метод позволяет проводить оценку коэффициентов теплопроводности и тепловой диффузии (температуропроводности) образцов несегнетоэлектрических материалов, расположенных на сегнетоэлектрическом кристалле $[8,9]$. Тепловые характеристики материала, через который проходит темпе- ратурная волна, определяются путем сравнения экспериментальных и расчетных форм пироотклика. При использовании в пироэлектрических исследованиях прямоугольно модулированного теплового потока пироотклик однородно поляризованного сегнетоэлектрика повторяет его форму, если глубина проникновения температурной волны в образец меньше одной трети толщины образца $d$, в противном случае наблюдается так называемый „Пленочный“ ${ }^{\circ}$ отклик $[6,7]$. Когда на сегнетоэлектрик помещен несегнетоэлектрический материал, в начале импульса пироотклика появляется „завал“, величина которого определяется толщиной и коэффициентами тепловой диффузии и теплопроводности данного материала $[8,9]$.

Зависимость пиротока от времени, т. е. его форма за один период модуляции теплового потока, рассчитывается по формуле

$$
I(t)=\frac{S}{d} \int_{0}^{d} \gamma \frac{\partial \Theta(t, x)}{\partial t} d x,
$$

где $\gamma$ - пирокоэффициент сегнетоэлектрика, $d-$ его толщина, $S$ - площадь электродов, $\Theta(t, x)$ - распределение температуры, которое находится из решения уравнения теплопроводности для случая многослойной системы с разными тепловыми характеристиками слоев, $x$ - координата (в направлении, перпендикулярном поверхности, на которую воздействует тепловой поток).

Решение задачи для двух слоев (несегнетоэлектрический материал-сегнетоэлектрик) представлено в работе [8]. Полученное решение применимо только в том случае, когда температурная волна не проникает в сегнетоэлектрический материал глубже чем на $\frac{1}{3} d$. Это условие выполняется для образцов с большим термическим сопротивлением. Как было показано в работе [9], 


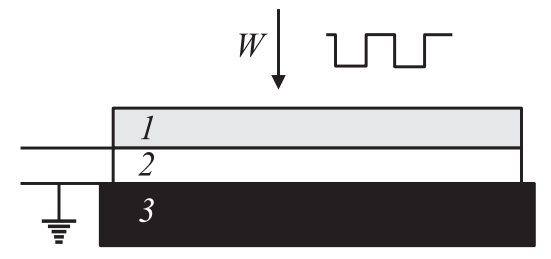

Рис. 1. Схема регистрации пироотклика. 1 - образец несегнетоэлектрического материала, 2 - сегнетоэлектрик (в эксперименте кристалл танталата лития), 3 - металлическая подложка.

количество тепла, прошедшего через образец, обратно пропорционально его коэффициенту теплопроводности. Кристаллы парателлурита относятся к диэлектрическим материалам, для которых характерны малые значения коэффициента теплопроводности [11]. Следовательно, для анализа их тепловых характеристик необходимо учитывать переход тепла в подложку [10], на которой расположена тыльная сторона сегнетоэлектрика, т. е. решать задачу теплопроводности для системы, состоящей из трех слоев (рис. 1).

В общем случае прохождения тепла через систему из $n$ слоев имеем систему $n$ уравнений теплопроводности

$$
\frac{\partial \Theta_{l}}{\partial t}=\alpha_{i} \frac{\partial^{2} \Theta_{i}}{\partial x^{2}} \quad \text { при } \quad x \in\left[x_{i-1}, x_{i}\right],
$$

где $x_{i}$ - координата конца $i$-го слоя, $i$ - порядковый номер слоя, $l_{i}=x_{i}-x_{i-1}-$ толщина $i$-го слоя $\left(l_{0} \equiv 0\right)$, $\alpha_{i}$ - коэффициент температуропроводности $i$-го слоя. Решение системы (2) находится с учетом граничных условий

$$
\begin{gathered}
-\left.k_{1} \frac{\partial \Theta_{1}}{\partial x}\right|_{x=0}=W(t), \\
\left.k_{i} \frac{\partial \Theta_{i}}{\partial x}\right|_{x=x_{i}}=\left.k_{i+1} \frac{\partial \Theta_{i+1}}{\partial x}\right|_{x=x_{i}}, \\
\left.\Theta_{l}\right|_{x=x_{i}}=\left.\Theta_{i+1}\right|_{x=x_{i}}, \\
\left.\frac{\partial \Theta_{n}}{\partial x}\right|_{x=h}=0 .
\end{gathered}
$$

Здесь $k_{i}-$ коэффициент теплопроводности $i$-го слоя, $h=\sum_{i=1}^{n} l_{i}$

$$
W(t)=W_{0} \frac{\tau}{T_{m}}\left(1+\sum_{n=1}^{\infty} \frac{\sin (n \omega \tau / 2)}{n \omega \tau / 2} \exp (\text { in } \omega t)\right)
$$

- зависимость мощности падающего на образец прямоугольно модулированного теплового потока от времени [12], $T_{m}$ - период модуляции теплового потока, $\tau$ - длительность светового промежутка $\left(\tau=T_{m} / 2\right)$, $\omega=2 \pi / T_{m}$ - циклическая частота, $W_{0}-$ плотность теплового потока.

Для системы (рис. 1) несегнетоэлектрический материал (1)-сегнетоэлектрик (2)-металлическая подложка (3) задача решалась с учетом условия $l_{2} \equiv d \ll l_{3}$, что упрощает решение, позволяя считать $l_{3} \rightarrow \infty$ [10].
В результате при выполнении граничных условий (3) имеем для пиротока сегнетоэлектрического материала, являющегося компонентом слоистой структуры (рис. 1),

$$
\begin{aligned}
I= & \frac{S W_{0} \gamma}{h} \operatorname{Re}\left\{\sum _ { n = 1 } ^ { \infty } \left\{\frac{\sin (n \omega \tau / 2)}{n \omega \tau / 2} \exp (i n \omega t) \frac{i n \omega}{\varphi_{2}}\right.\right. \\
& \left.\times\left[\frac{\operatorname{ch}\left(\varphi_{2} l_{2}\right)-\operatorname{ch}\left(\varphi_{2} l_{1}\right)}{C+B A}-\frac{\operatorname{sh}\left(\varphi_{2} l_{2}\right)-\operatorname{sh}\left(\varphi_{2} l_{1}\right)}{C / A+B}\right]\right\},
\end{aligned}
$$

где

$$
\begin{gathered}
A=\frac{k_{2} \varphi_{2} \operatorname{ch}\left[\varphi_{2} l_{2}\right]+k_{3} \varphi_{3} \operatorname{sh}\left[\varphi_{2} l_{2}\right]}{k_{3} \varphi_{3} \operatorname{ch}\left[\varphi_{2} l_{2}\right]+k_{2} \varphi_{2} \operatorname{sh}\left[\varphi_{2} l_{2}\right]} \\
B=k_{2} \varphi_{2} \operatorname{sh}\left[\varphi_{2} l_{1}\right] \operatorname{ch}\left[\varphi_{1} l_{1}\right]-k_{1} \varphi_{1} \operatorname{ch}\left[\varphi_{2} l_{1}\right] \operatorname{sh}\left[\varphi_{1} l_{1}\right], \\
C=k_{1} \varphi_{1} \operatorname{sh}\left[\varphi_{2} l_{1}\right] \operatorname{sh}\left[\varphi_{1} l_{1}\right]-k_{2} \varphi_{2} \operatorname{ch}\left[\varphi_{2} l_{1}\right] \operatorname{ch}\left[\varphi_{1} l_{1}\right] .
\end{gathered}
$$

Здесь $\varphi_{m}=(1+i) \sqrt{n \omega / 2 \alpha_{m}}, m=1,2,3$.

$\mathrm{B}$ качестве пироэлектрического материала использовался образец кристалла танталата лития (TL) размером $10 \times 10 \mathrm{~mm} \mathrm{c}$ толщиной $1 \mathrm{~mm}$. На рис. 2 показаны расчетные формы пироотклика TL в зависимости от коэффициента теплопроводности $k_{1}$ помещенного на
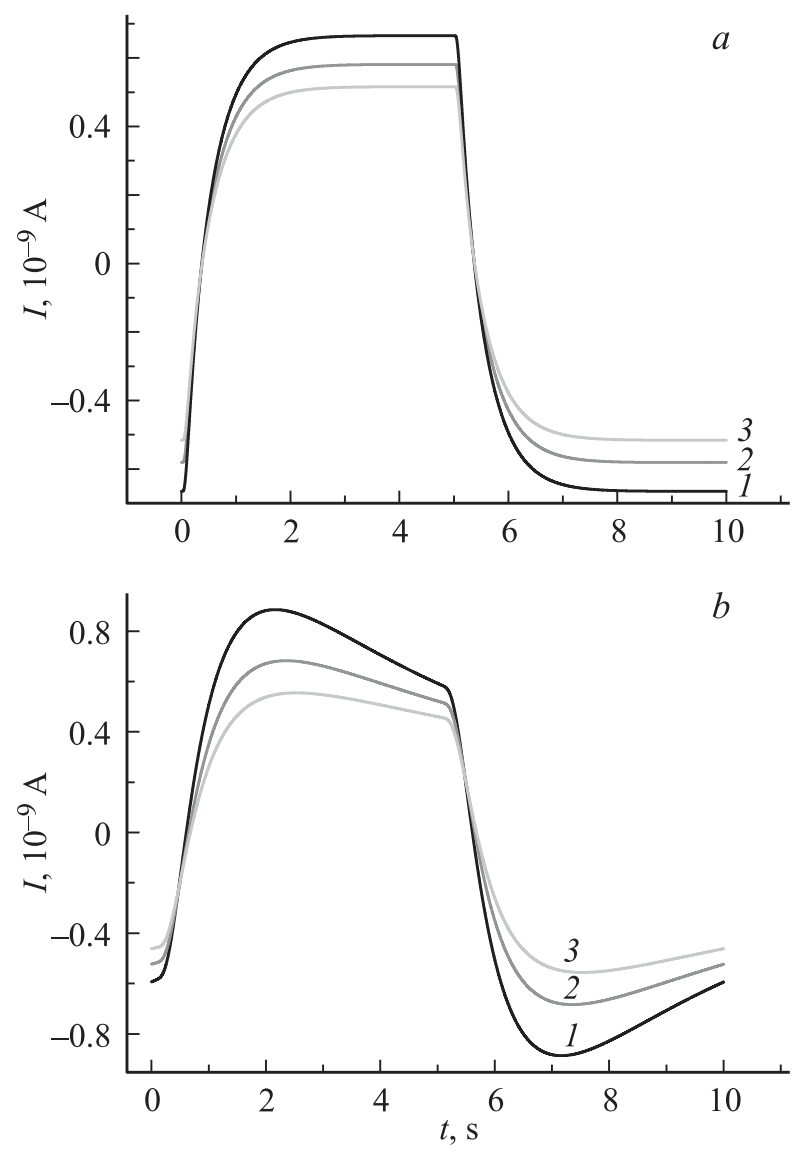

Рис. 2. Расчетные формы пироотклика TL при постоянном значении коэффициента тепловой диффузии и различных значениях коэффициента теплопроводности несегнетоэлектрического материала: $a-$ расчет проведен без учета перехода тепла в металлическую подложку, $b-$ с учетом. Обозначение кривых поясняется в тексте. 

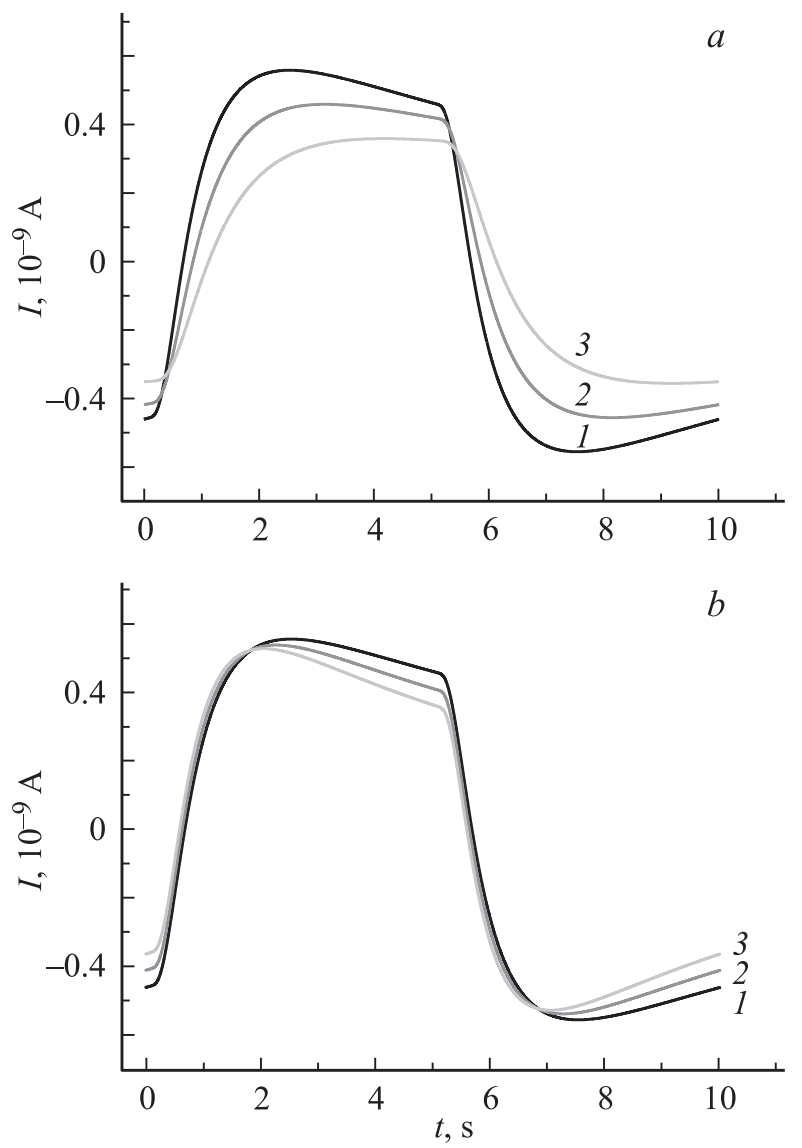

Pис. 3. Расчетные формы пироотклика TL. $a-$ при постоянном значении коэффициента теплопроводности и различных значениях коэффициента тепловой диффузии материала $\left(\alpha_{1}^{1}>\alpha_{1}^{2}>\alpha_{1}^{3}\right.$, верхние индексы соответствуют номерам кривых), $b$ - при постоянных тепловых характеристиках материала и различном коэффициенте теплопроводности подложки $\left(k_{3}^{1}<k_{3}^{2}<k_{3}^{3}\right)$. Расчет проведен с учетом перехода тепла в подложку.

него материала, через который проходит температурная волна $\left(k_{1}^{1}<k_{1}^{2}<k_{1}^{3}\right.$, верхние индексы в обозначениях коэффициентов теплопроводности соответствуют номерам кривых на рис. 2). Рис. 2, $a$ относится к образцу с большим термическим сопротивлением. Когда температурная волна не проникает в TL глубже чем на $\frac{1}{3} d$, в расчетной формуле переход тепла в подложку не учитывается (используется формула, полученная в работе [8]). Рис. 2, $b$ относится к образцу с малым термическим сопротивлением, в расчетной формуле учтен переход тепла в металлическую подложку. Как видно из расчетных кривых, форма пироотклика определяется глубиной прохождения температурной волны в TL (меньше чем на $\frac{1}{3} d$ или больше), тогда как значение пиротока обратно пропорционально величине коэффициента теплопроводности материала, помещенного на $\mathrm{TL}$, и прямо пропорционально величине температуропроводности (рис. 3,a). В отличие от коэффициента теплопроводности величина коэффициента температуро- проводности влияет как на величину пироотклика, так и на его форму. Крутизна „завала“, наблюдаемого в конце полупериода пироотклика, зависит также и от коэффициента теплопроводности металлической подложки, на которую помещен TL (рис. $3, b)$.

\section{3. Экспериментальные результаты и их обсуждение}

Исследуемые образцы монокристалла парателлурита имели размер $1 \times 4 \times 5 \mathrm{~mm}$ (поверхности $4 \times 5 \mathrm{~mm}$ соответствовали кристаллографическим плоскостям [110], [11̄0], [010] и [001]). На рис. 4 представлены пироотклики TL, наблюдаемые при прохождении температурной волны (частотой $0.1 \mathrm{~Hz}$ ) через образцы парателлурита различных кристаллографических ориентаций. Поскольку пироотклики, наблюдаемые при прохождении температурной волны в направлениях [110] и [010], совпадают, последний на рис. 4 не представлен. С точки зрения кристаллофизики направления $[110],[010]$ и $[1 \overline{1} 0]$, являющиеся осями второго порядка, ортогональными оптической оси, направленной вдоль [001], должны быть эквивалентны. В то же время формы пирооткликов практически совпали только при прохождении температурной волны через пластины, вырезанные перпендикулярно плоскостям [110] и [010]. Согласно результатам, представленным на рис. 4, теплофизические характеристики отличаются от аналогичных характеристик в направлениях [110] и [010] не только для направления $[001]$, но и для направления $[1 \overline{1} 0]$, вдоль которого происходило вытягивание кристалла в процессе роста.

Для количественной оценки значений тепловых характеристик было проведено сравнение экспериментальных форм пирооткликов с расчетными (рис. 5). Поскольку форма пироотклика TL, наблюдаемая при прохождении температурной волны через образцы парателлурита,

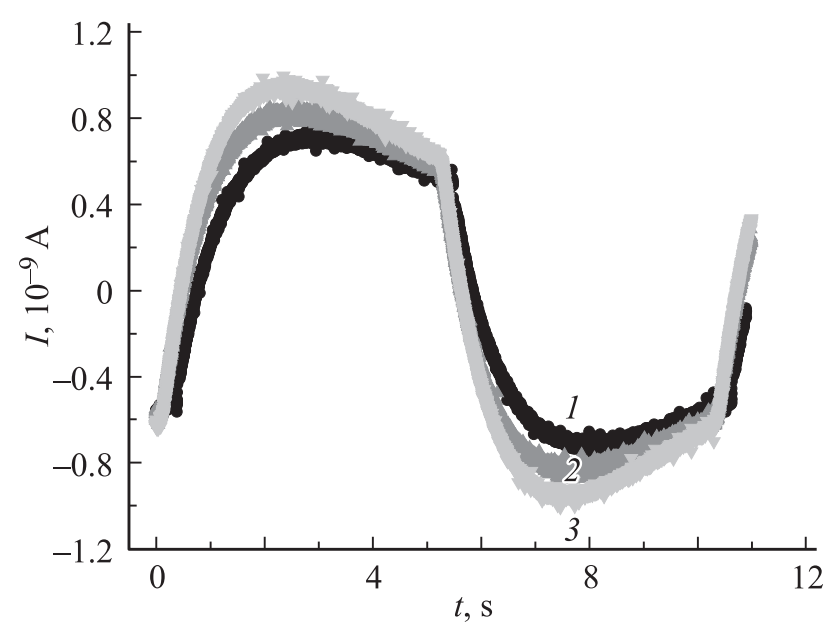

Pис. 4. Пироотклик TL, фиксируемый при прохождении температурной волны через образцы кристалла парателлурита. Кривая $1-$ кристаллографическое направление [110], $2-[1 \overline{1} 0], 3-[001]$. 
Сравнение тепловых характеристик и диэлектрической проницаемости кристалла парателлурита в разных кристаллографических направлениях

\begin{tabular}{c|c|c|c}
\hline $\begin{array}{c}\text { Кристаллографическое } \\
\text { направление }\end{array}$ & $\begin{array}{c}\text { Коэффициент } \\
\text { тепловой диффузии, } \mathrm{m}^{2} / \mathrm{s}\end{array}$ & $\begin{array}{c}\text { Коэффициент } \\
\text { теплопроводности, } \mathrm{W} / \mathrm{m}^{2} \cdot \mathrm{K}\end{array}$ & $\begin{array}{c}\text { Диэлектрическая } \\
\text { проницаемсть }\end{array}$ \\
\hline$[110]$ & $2.3 \cdot 10^{-7}$ & 0.45 & 24 \\
{$[010]$} & $2.3 \cdot 10^{-7}$ & 0.45 & 23 \\
{$[1 \overline{1} 0]$} & $2.3 \cdot 10^{-7}$ & 0.25 & 30 \\
{$[001]$} & $2.3 \cdot 10^{-7}$ & 0.04 & 37
\end{tabular}

имеет четко выраженный „завал“ в конце полупериода, для расчетов использовалась формула (5). Значения теплофизических характеристик, при которых расчетные формы пироотклика совпали с экспериментально наблюдаемыми, приведены в таблице. В таблице также представлены значения диэлектрической проницаемости, полученные для этих пластин на измерителе иммитанса E7-20 в диапазоне частот $25 \mathrm{~Hz}-100 \mathrm{kHz}$. Как и следовало ожидать, существенные различия в значениях как коэффициента теплопроводности, так и диэлектрической проницаемости наблюдаются в направлении [001]. Интересно отметить, что если значения диэлектрической проницаемости для этого направления максимальны (в 1.5 раза больше, чем для [110] и [010]), то коэффициент теплопроводности минимален и его значение отличается от измеренных в других направле- ниях на порядок. Зависимости коэффициента температуропроводности от кристаллографического направления установлено не было.

Полученная зависимость коэффициента теплопроводности от кристаллографического направления хорошо согласуется с данными по анизотропии скорости роста кристаллов парателлурита из расплава [13], из которых следует, что наиболее медленно растущими (при одном и том же переохлаждении) гранями для этих кристаллов являются грани $\{110\}$.

На рис. 6 показан кристалл парателлурита, выращенный в направлении [1ํㅣ, а затем оставленный при выключенном нагревателе в остывающем расплаве на три минуты. Хорошо видны диаметрально противоположные дендритообразные выступы, быстро выросшие в направлениях [001]. В ортогональных же направле-
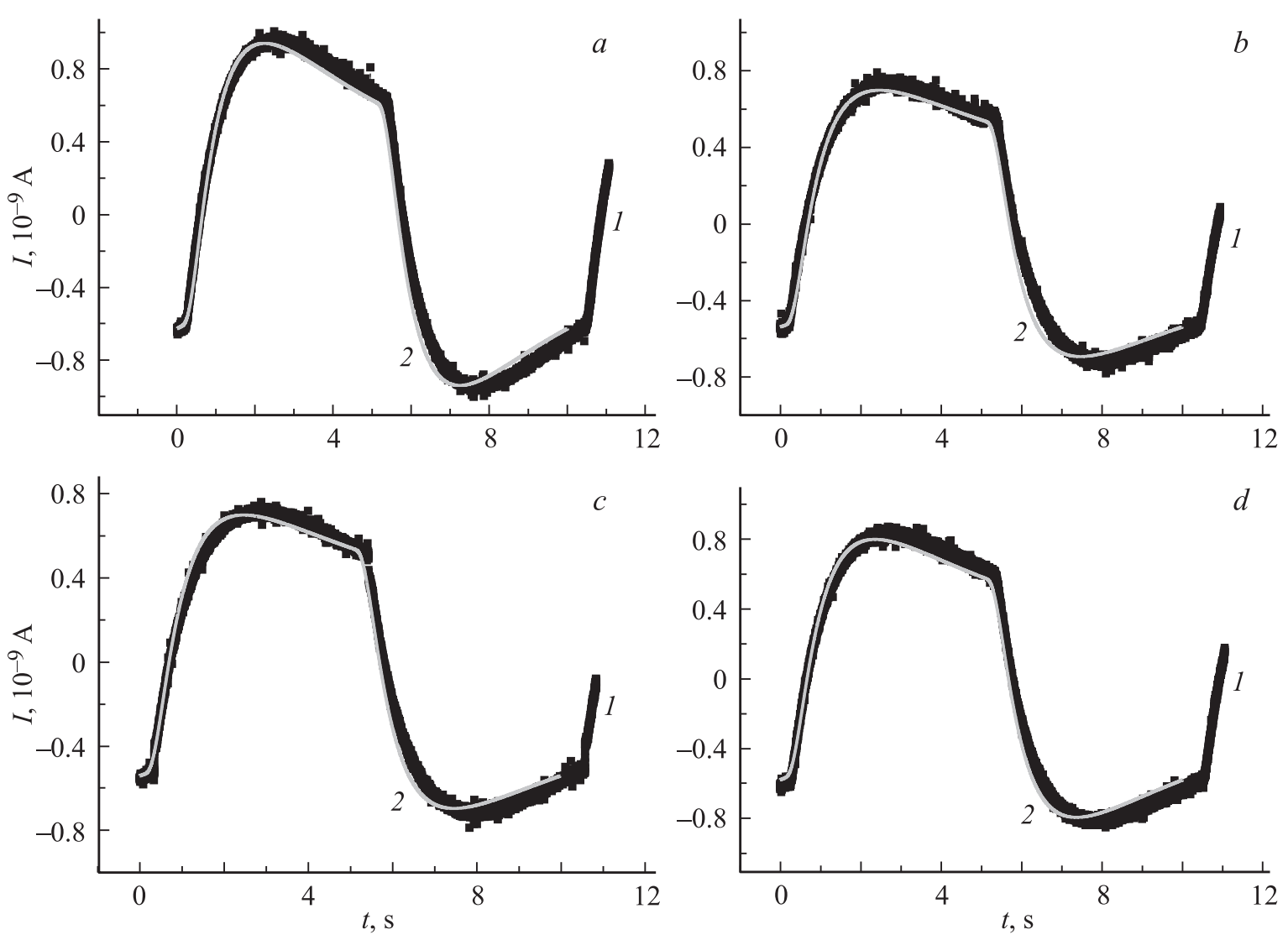

Рис. 5. Экспериментальные (1) и расчетные (2) формы пироотклика TL при прохождении температурной волны через образцы парателлурита в кристаллографических направлениях [001] (a), [010] (b), [110] (c) и [1̄ㅣ (d). 


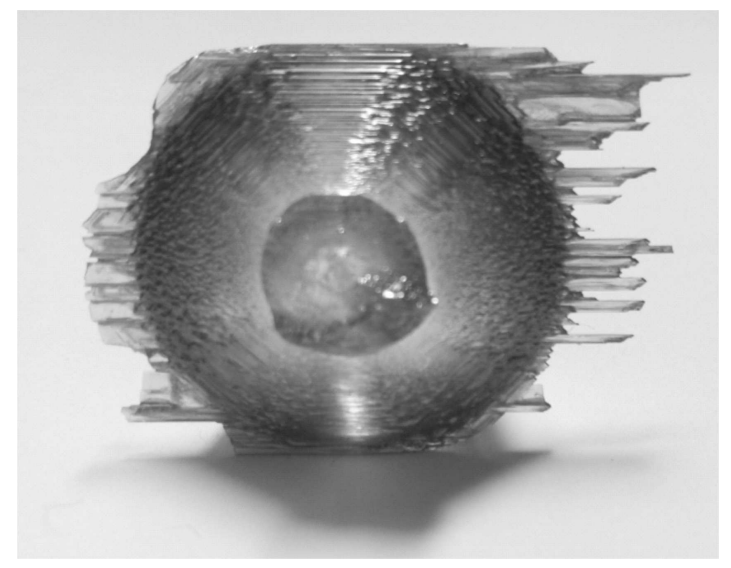

Pис. 6. Монокристалл парателлурита, вытянутый в нижней части при больших переохлаждениях расплава, с наростами в направлении [001].

ниях $[010],[110]$ и $[1 \overline{1} 0]$ скорость роста по крайней мере на порядок меньше. В таких условиях теплообмена при наличии быстро остывающего расплава имеет место высокое переохлаждение расплава вблизи фронта кристаллизации. Градиент температуры меняет знак, и теплоотвод будет осуществляться в направлении от твердой фазы в жидкую. В направлениях [010], [110], [1ํㅣ, отвечающих более высоким коэффициентам теплопроводности, переохлаждение на фронте кристаллизации нивелируется теплом, отводящимся от кристалла. Поскольку в направлении [001] коэффициент теплопроводности на порядок меньше, чем в других кристаллографических направлениях, теплопередача из кристалла в расплав в прилегающих областях снижена, и уровень переохлаждения вблизи фронта кристаллизации выше. Скорость роста дендритов напрямую связана с величиной переохлаждения [14], и очевидно, что именно в направлении [001] рост дендритов должен происходить с максимальной скоростью.

Здесь также существен тот факт, что плоскости $\{001\}$ в парателлурите являются атомно-шероховатыми и растут по нормальному механизму со скоростью, прямо пропорциональной переохлаждению расплава, в то время как плоскости $\{110\}$ являются гладкими, сингулярными и растут по тангенциальному механизму, требующему существенно большего переохлаждения расплава [13].

\section{4. Заключение}

В работе показано, что при использовании пироэлектрического метода TSW для оценки значений коэффициентов теплопроводности и тепловой диффузии несегнетоэлектрических материалов с малыми значениями коэффициента теплопроводности необходимо при решении уравнения теплопроводности учитывать изменение теплового потока с тыльной стороны сегнетоэлектрического материала. Для учета перехода тепла в металли- ческую подложку решена задача теплопроводности для системы, состоящей из трех слоев.

Установлено, что величины коэффициентов теплопроводности и диэлектрической проницаемости пластин кристалла парателлурита зависят от кристаллографического направления. Вытягивание кристалла в процессе роста оказывает влияние на значения его физических характеристик. Зависимость коэффициента теплопроводности от кристаллографического направления хорошо коррелирует с аналогичной зависимостью для диэлектрической проницаемости. Максимальное значение диэлектрической проницаемости наблюдается в направлении [001], тогда как коэффициент теплопроводности в данном направлении имеет минимальное значение, причем если значение диэлектрической проницаемости изменяется в пределах 50\%, то величина коэффициента теплопроводности - в 11 раз.

Различие характеристик (коэффициентов теплопроводности и диэлектрической проницаемости), измеренных в двух кристаллографически тождественных направлениях — вдоль (направление [1피) и ортогонально (направления [110] и [010]) оси були, является следствием дефектов реальной структуры и неоднородного (секториального) их распределения в объеме, обусловленного физическими различиями процессов нарастания кристалла парателлурита по радиусу и в вертикальном направлении.

Полученные данные о теплопроводности кристаллов парателлурита наиболее важны для решения другой задачи - расчета тепловых полей в светозвукопроводах работающих акустооптических устройств на основе этих кристаллов.

\section{Список литературы}

[1] Л.Н. Магдич, П.И. Шницер, В.Н. Сасов. Электронная техника. Сер. Квантовая электроника 10, 1, 44 (1975).

[2] P. Maák, T. Takács, A. Barócsi, E. Kollár, V. Szekely, P. Richter. Opt. Commun. 266, 419 (2006).

[3] P. Maák, T. Takács, A. Barócsi, E. Kollár, P. Richter. Ultrasonics 51, 441 (2011).

[4] R. Jiang, Z. Zhou, X. Ly, Z. Shogun, H. Zhifeng, H. Zhou. Ultrasonics 52, 643 (2012).

[5] О.В. Малышкина, А.А. Мовчикова. ФТТ 51, 1307 (2009).

[6] O.V. Malyshkina, A.A. Movchikova, R.M. Grechishkin, O.N. Kalugina. Ferroelectrics 400, 63 (2010).

[7] О.В. Малышкина. ФТТ 52, 704 (2010).

[8] А.А. Мовчикова, О.В. Малышкина, О.Н. Калугина. Поверхность. Рентгеновские, синхротронные и нейтронные исследования 6, 1, 37 (2012).

[9] О.В. Малышкина, О.Н. Калугина, М.Ю. Гавалян, И.А. Каплунов. ФТТ 57, 2102 (2015).

[10] О.В. Малышкина, А.А. Мовчикова, Н.Б. Прокофьева, О.Н. Калугина. Вестн. ТвГУ. Сер. Физика 7, 48 (2009).

[11] А.И. Пехович, В.М. Жидких. Расчеты теплового режима твердых тел. Энергия, Л. (1976). 352 с.

[12] H.I. Zajosz, A. Grylka. Infrared Phys. 23, 271 (1983).

[13] А.И. Колесников, И.А. Каплунов, И.А. Терентьев. Кристаллография 49, 229 (2004).

[14] Р. Лодиз, Р. Паркер. Рост монокристаллов. Мир, М. (1974). 540 c. 